\title{
Factors Affecting Vision and Visio-Spatial Intelligence(VSI) in Sport: A Review of the Literature
}

\author{
Lourens Millard (iD) ${ }^{1,}$, Ina Shaw (iD) ${ }^{1}$, Gerrit Jan Breukelman (iD) ${ }^{1}$ and Brandon Stuwart Shaw (iD) ${ }^{1}$ \\ ${ }^{1}$ Department of Human Movement Science, University of Zululand, Richards Bay, South Africa \\ "Corresponding author: Department of Human Movement Science, University of Zululand, Richards Bay, South Africa. Email: millardl@unizulu.ac.za
}

Received 2020 February 09; Revised 2020 May 09; Accepted 2020 May 28.

\begin{abstract}
Sport has become increasingly competitive, prompting the need to determine, as far as possible, any likely performance advantage. While the focus of athletic research, testing, and training is on the physiological and physical characteristics of the sport, visual abilities not only affect sport performance directly, but also affect the acquisition of motor skills. Vision, and visual-spatial intelligence (VSI), are a relatively new and underexplored area of athletic performance. As with physiological and physical parameters, a range of factors affect vision and VSI in sporting activities. This review of the literature is a first attempt to summarize and compile an overview of the factors affecting vision and VSI in athletes, covering those previously connected with sport, as well as those hitherto not associated with athletic activities, but that could also play a part in sports performance. The evidence from this review suggests that while current research still tends to focus on single factors affecting vision and VSI, a large number of such factors have been identified that could affect vision and VSI. This offers new opportunities for researchers to investigate the effects of a combination of factors, and for conditioning and/or sports vision specialists to explore further possibilities for competitive advantage.
\end{abstract}

Keywords: Athletic Performance, Decision Making, Optometric Intervention, Sport Performance, Sports Vision, Visual Abilities

\section{Context}

Significant debate still surrounds the possible reasons for superior athletic or sports performance by successful athletes, particularly in ball sports, such as rugby, cricket, and tennis (1). Unsurprisingly, experts in these sports believe that in order to perform optimally, a player needs a "great eye", superb vision or excellent peripheral vision (1). Athletes can spend thousands of hours in physical training to improve their physical attributes; however, if their vision or visual processing capabilities are inadequate, their physical training may not be optimized, and their athletic performance will suffer (2). The eye is the most important receptor in the human body (3) and as such, the human visual information processing system has been recognized as playing a critical role in athletic performance (4-6) and has generated concomitant interest in the area of sports vision (2).

This reliance and importance of the visual system necessitates the need to determine the factors that affect an athlete's ability to obtain and respond to appropriate visual stimuli. Conversely, challenges in the ability to obtain and process specific and appropriate visual stimuli lead to incorrect or ineffective movement outcomes $(5,6)$.
To date, research has focused on individual factors that affect vision and VSI. However, a combination of factors may play their part and could warrant a more holistic approach. This review of the literature novelly attempts to summarize and compile an overview of the factors affecting vision and VSI in athletes, covering those previously connected with sport, as well as those hitherto not yet associated with athletic activities, but that could also play a part in sports performance.

\section{Objectives}

The aim of this review is to identify and summarize a body of relevant, previously researched factors that have or have not yet been associated with athletic activities, and that could affect vision and VSI, and thus athletic performance.

\section{Methods}

A review of the scholarly literature related to the factors affecting vision and VSI was performed using standardized procedures (7). To identify potentially relevant articles for focused searching and to reduce the potential for 
random errors and bias, data abstraction was performed independently by two of the authors. This was to ensure consistent application of the inclusion and exclusion criteria and to eliminate efficiently all obviously ineligible publications. These two authors reviewed each citation and, whenever an abstract was available, the abstract. These authors compared decisions for inclusion and discrepancies in inclusion were resolved by discussion and re-review, and by consulting a third author when consensus could not be reached. Following this, a careful review of the full-text publications was conducted.

To review the scholarly literature related to factors affecting vision and VSI an electronic search was performed on the following databases that were available to the researchers: PubMed (1966-June 2019), Sports Discuss (1975June 2019), Science Direct, Current Contents, CISTI Source (1993-June 2019), Google Scholar, Cochrane Database of Systematic Reviews, EBM Reviews, and international ecatalogs. A keyword search yielded MeSH headings: "factors affecting vision" "sport vision", "ophthalmology", "visual disturbances", "visual factors", "visual pain", "visual temperature", "humidity and vision", "vision and diet", "visual psychology", "sleep and vision", "hydration and vision", "visual infections", "hormones and vision", "retinal disorders", "light sensitivity", "age and vision", and "fatigue and vision" which were combined and explored. Searches were restricted to peer-reviewed articles in the English language. Articles included in this review were required to describe factors that had a direct impact on vision, or the visual capabilities of individuals.

\section{Results}

The electronic searches yielded 1,577 citations, out of which only 46 full-text English-language articles were deemed relevant for use in this study. Following the removal of duplicates and review of full-text versions, a total of 37 articles remained for physiological factors that affect vision, five for environmental factors that affect vision, and four for psychological factors that affect vision (Table 1).

\section{Discussion}

To date, studies related to vision and VSI have tended to focus on single factors only in isolation. This review has novelly identified and summarized information about previously researched factors related to sports, as well as others that were previously not associated with having an effect on vision and VSI in relation to athletic performance.

Athletes competing in ball sports, such as basketball, rugby, volleyball, and netball require a variety of visual skills such as catching, passing and kicking, to enable them to advance the ball beyond the opposing team's defensive line (53). Furthermore, athletes that compete in racquet sports, such as tennis, badminton, and table tennis, are exposed to multisensory visual constraints, where they are required to perform in spite of visual uncertainty, thereby tasking their ability to predict the event (54). These events can be seen as an interaction between two systems, namely, a "software" system of acquired skill prediction and "hardware" system of intrinsic visual ability (54). Both systems need to work in harmony in order to perform visual tasks to enable optimal performance. Thus, whether athletes compete in team sports (rugby) or individual sports (tennis), experts suggest that they require a "great eye", superb vision or excellent peripheral vision (1). To measure the VSI in athletes accurately, it is important to consider the factors that affect vision.

Vision is created by the brain and through the visual pathways that consist of the optic nerve, optic chiasm, optic tract, optic radiation, and the visual cortex in the occipital lobes (55). Thus, any condition that affects the brain or the visual pathway is the most obvious factors affecting vison and VSI in athletes.

The most common factors affecting vision and VSI relate to the eye itself and conditions associated with the eye. However, the multitude of such conditions that may affect vision are beyond the scope of the present study, and this review focuses on maladies that most often affect athletic populations. The conditions that will be discussed in this study include amblyopia, glaucoma, colorblindness, refractive error, recent eye surgery, dry eye, and eye-structure variance. Amblyopia ("lazy eye") is a neurodevelopmental disorder traditionally characterized by low-level deficits, including reduced visual acuity, stereoacuity, and contrast sensitivity (56). It is caused by an abnormal visual experience during early childhood when the input to the central nervous system from one eye is suppressed. Individuals with amblyopia have shown to have deficits in the perception of global motion (8), processing of global contours (9), and shape detection (10). A combination of all of these deficits will have a major influence on visual performance in athletes. Glaucoma is a neurodegenerative disorder of the optic nerve, which is caused by retinal ganglion cell deaths, which leads to characteristic patterns of visual field loss (11). Glaucoma can be caused by multiple factors including a chemical or blunt injury (as is common in sports) to the eye, severe eye infection (as is common during sporting events during extreme environmental conditions), blocked eye blood vessels, and inflammatory conditions (11). Colorblindness is caused if one, two, or three of these types of cones in the retina is either missing or dys- 


\begin{tabular}{|c|c|}
\hline Factors & Details \\
\hline \multicolumn{2}{|l|}{ Physiological factors } \\
\hline \multirow{6}{*}{ Eye conditions } & Amblyopia causes a deficit in perception of global motion, processing of global contours, and shape detection (8-10). \\
\hline & Glaucoma causes gradual loss of vision (11). \\
\hline & Color blindness causes performance decrease without special provisions (12). \\
\hline & Refractive error causes blurred vision (13). \\
\hline & Dry eye affects tear fluid osmolarity (14). \\
\hline & Eye-structure variance affects the corneal stroma (15). \\
\hline Pain & Headaches affect vision (16-19). \\
\hline Sleep deprivation & Leads to modifications in specific areas of the brain (20-23). \\
\hline \multirow{4}{*}{ Infection and diseases } & Infection affects colour vision and contra sensitivity (24). \\
\hline & HIV alters retinal nerve fiber (25). \\
\hline & Fungal infections lead to blurred vision and a decrease in the visual field (26). \\
\hline & Conjunctivitis leads to vision loss $(27,28)$. \\
\hline \multirow{2}{*}{ Endocrine system } & Hyperthyroidism or hypothyroidism causes multiple visual impairments including peripheral vision loss (29). \\
\hline & Thyroid hormone levels affect the cones of the eyes (30). \\
\hline Retinal detachment & Causes complete vision loss (31). \\
\hline Aging & Causes muscle deterioration, blurred vision, and "wear and tear" of the eye $(32,33)$. \\
\hline \multirow{4}{*}{ Diet } & Certain foods can influence vision (34). \\
\hline & Docosahexaenoic acid (DHA) causes improvements in the retina $(35,36)$. \\
\hline & DHA deficiency causes problems with vision (37). \\
\hline & Caffeine can enhance visual capabilities and reduce visual fatigue (38). \\
\hline Exercise & Prolonged exercise leads to brain fatigue (38). \\
\hline \multirow{2}{*}{ Medication } & Can lead to loss of central vision (39). \\
\hline & May cause brain fog and lead to a decrease of visual ability (40-43). \\
\hline \multicolumn{2}{|l|}{ Environmental factors } \\
\hline \multirow{2}{*}{ Temperature } & The lens of the eye is affected by changes in temperature (44). \\
\hline & Increase in temperature causes light scattering from lens proteins (45). \\
\hline \multirow{3}{*}{ Lighting } & Light-emitting diode (LED) bulbs improve visual acuity (46). \\
\hline & Visual stimuli are influenced by the chromaticity of light $(47,48)$. \\
\hline & Increasing the quality of artificial light positively affected vision (49). \\
\hline \multicolumn{2}{|l|}{ Psychological factors } \\
\hline Anxiety & Leads to "tunnel vison" (50). \\
\hline \multirow{2}{*}{ Stress } & Causes a decrease in visual acuity and progressive vision loss (51). \\
\hline & Leads to temporary vision loss (52). \\
\hline
\end{tabular}

functional (57). Problematically, athletes with colorblindness need special provisions to be made during training, such as to adjust uniforms or equipment (i.e., balls) to compensate for possible confusion (12). Refractive error occurs when the optical system of the non-accommodating eye fails to bring parallel rays of light into focus on the fovea
(13). This leads to myopia and hyperopia, which are states of refractive error in which the optical system of the eye brings parallel rays of light into focus anterior and posterior to the fovea, respectively, resulting in blurred vision (13), effectively resulting in an increased chance of mistakes made during athletic training and competition. Dry 
eye is common among athletes. It affects tear fluid osmolarity and arises out of even modest changes in whole-body hydration (14). These changes have various causes, including exercise modality, type of play, level of competition, metrological conditions (i.e., humidity and environmental temperature), and type of sport (58). Since individuals with dry eye, which indicates suboptimal hydration, have higher plasma osmolality than those without dry eye, it can be safely stated that if an athlete hydrates properly, this condition could be prevented (59). A further hydrationrelated feature is eye-structure variance. Eye-structure variance also affects vision since the corneal stroma, is highly dependent on an individual's hydration status (15), and any change in corneal hydration status can result in variations in central corneal thickness (60). Even when overhydration exists, the optically transparent corneal stroma swells, and a lowering of hydration is needed to return it to its normal thickness (61).

In addition to high temperatures causing fluid loss and affecting whole-body hydration, temperature itself, in the form of ambient and body temperature, is an important factor that can profoundly affect vision and VSI. Athletes generally train or compete outdoors or in venues without temperature control for extended periods of time. Problematically, if the ambient temperature rises beyond a certain threshold, proteins denature and may not function properly (44), which means that proteins of the lens of the eye are also susceptible to changes in temperature. Lowering the temperature of the lens too much, as during training or when competing in cold conditions, causes the formation of a temporary or "cold" cataract that disappears when the temperature is normalized (44). Even a slight increase in body temperature above the physiological level of $37^{\circ} \mathrm{C}$ increases light scattering from lens proteins because of protein aggregation and denaturation (45). Thus, it is logical to suggest that relationships exist between vision and VSI on the one hand, and environmental temperature and eye temperature on the other (62).

With regards to the brain and vision in athletes, any factor that creates clouding of consciousness may affect vision and VSI in athletes. Clouding of consciousness/brain fog is not a medical condition itself, but rather a symptom of other medical conditions (63). Clouding of consciousness is a type of cognitive dysfunction involving: memory problems, lack of mental clarity, poor concentration, and inability to focus. There are numerous explanations for why brain fog occurs and includes inter alia: stress, lack of sleep, hormonal changes, diet, medication, and medical conditions (63).

Anxiety is common when athletes doubt their ability to cope with external or internal demands (64), and can affect performance by drawing attention away from relevant task-related information to task-irrelevant cues instead (50). In essence, increasing anxiety can lead to "tunnel vision", in which an athlete focuses on internal or external distracting stimuli instead of concentrating on taskrelevant information (50). In addition, Bittner et al. (51) have found that visual acuity can be influenced by stress and individuals with high levels of stress display progressive losses in vision. Moschos (52) has further demonstrated that when stress leads to profound suffering, vision disorders can arise; even to the extent of temporary loss of vision. Problematically, this stress is an inherent aspect of sports performance (65).

A large body of research has been published on the effect of sleep deprivation on both physical and mental performance (66). However, it also appears that sleep deprivation may affect vision and VSI since functional imaging studies during cognitive tasks have shown that total sleep deprivation leads to modifications in specific areas of the brain. Among the main ones affected are the frontal and parietal cortices (20). An individual deprived of sleep for just 24 hours suffers a significant decrease in glucose metabolism in the prefrontal and parietal cortices during the performance of a difficult arithmetic working memory activity (21). It seems likely, therefore, that other cognitive tasks involving the frontal-parietal network, such as visiospatial attention (necessary for visually searching for information during athletic competition) could also be affected $(22,23)$.

The endocrine system can have a number of detrimental effects on vision; specifically, hyperthyroidism and hypothyroidism, can lead to not only poor quality of liferelated but also affect an athlete's vision (67). This is because these conditions can result in bulging eyes, decreased vision, distorted vision, double vision, loss of peripheral vision, a dark curtain or veil that blocks vision, excess watering of the eye, pain in the eye, and unusual red eyes (29). Individuals with higher levels of thyroxine are at increased risk of age-related macular degeneration (AMD) and other retinal changes. Thyroid hormone levels also appear to affect the ongoing development and regulation of the eye's cones (that is, cells responsible for color vision) (30).

Diet is a factor not always associated with vision. However, several studies have demonstrated that eating certain foods can influence vision (34). Specifically, diets high in mercury, have been found to be detrimental to visual acuity, whereas the consumption of omega-3 fatty acids have been associated with laying the foundation for the development and maintenance of the visual and ocular system (34). Docosahexaenoic acid (DHA) should be considered 
an essential part of an athlete's diet as it contains polyunsaturated fatty acids, which enrich not only the brain, but also the retina and specifically the photoreceptor cells (3537). Caffeine is a common ergogenic aid utilized by athletes, since even a moderate dose of it prevents fatigue in the skeletal muscle system and improves athletic performance (68). The effect of caffeine is no different in the eye, and it has been demonstrated to result in fatigue-induced reductions in the velocity of saccades ("voluntary, highvelocity eye movements that allow rapid changes in fixation") and the quick ("resetting eye movements") phase of optokinetic nystagmus (OKN) (38). However, it has been noted that the effects of both fatigue and caffeine on oculomotor control appear to be independent of the processes supporting visual attention and visual perception (38).

Medications such as benzodiazepines (40), anticholinergics (41), antipsychotics and mood-stabilizers (42), and opiate pain medications (43) may cause brain fog and lead to a decrease of visual ability. There are multiple other medications affecting vision, including, but not limited to, antihyperglycemic agents such as corticosteroids (chloroquine and hydroxychloroquine), antirheumatic medications, medications implicated in optic neuritis and atrophy, medications with an anticholinergic action; oral contraceptives, and topical medications with systemic effects (39). Athletes with hyperglycemia may use medications such as chloroquine and hydroxychloroquine which may cause irreversible maculopathy with resultant loss of central vision.

Brain fog can be caused by multiple conditions including anemia (69), diabetes (70), lupus (71), multiple sclerosis (72), arthritis (73), Alzheimer's disease (74), hypothyroidism (75), and migraines (76). Athletes are commonly influenced by anemia, diabetes, migraines, and hypothyroidism. If red blood cells do not deliver enough oxygen to the brain, due to iron deficiency anemia, an athlete may experience shortness of breath and brain fog. Recent clinical evidence shows that individuals with diabetes have increased incidences of vascular dementia, ventricular hypertrophy, lacunar infarcts, and hemorrhage, all of which leads to a decrease in brain function (77). Athletes with diabetes need to be aware that the condition can lead to brain dysfunction, and need to be monitored and treated accordingly. Brain structure and function are altered in hypothyroid patients, with decreased hippocampal volume, cerebral blood flow, and function globally and in regions that mediate attention, visuospatial processing, working memory, and motor speed (75). Thus, athletes with hypothyroidism may experience brain fog, which in turn influences vision, and can lead to a decrease in performance. Pain, in the form of headaches or migraines due to a concussion that can occur on the field of play, has been shown to have associated visual features, which include light sensitivity (16). According to a study by Queiroz et al. (17), more than half of all patients with headaches or migraines have blurred vision. This is caused by the imbalance in sympathetic and parasympathetic systems, and may be due to tear film changes (18). Headache or migraine pain and ocular symptoms can be connected by two factors: first, trigeminal activation, which causes eye pain and second, autonomic dysfunction in either the sympathetic or parasympathetic pathway that generates autonomic symptoms such as pupillary changes, lacrimation, redness of the eye, and even blurred vision (19). Some individuals have transient neurological disturbances called auras migraines (76). Auras can cause visual, language, motor, and sensory disturbances as well as brainstem symptoms such as dysarthria, vertigo, tinnitus, ataxia, and double vision (76). Thus, those individuals responsible for the care and training of athletes should be aware, when athletes receive a blow to the head, that headache or migraines are likely to occur, and that vision can be affected.

A multitude of further medical conditions affect vision. Ocular opportunistic infections are especially common in individuals with human immunodeficiency virus (HIV) (24). This may prove problematic for South African sport and athletes, since South Africa already has a $37 \%$ prevalence rate of HIV for adults aged 15 to 49 and such prevalence rates may be even higher in athletes due to their risk of infection based on behaviors associated with participation in their sport and away from competition (78). HIV-associated "neuroretinal disorder" results in changes in vision because the retinal nerve fiber layer is altered by the virus, causing a decrease in the visual field(25). Fungal infections, can affect vision in a way that dermatophytes can infect sections of the eyelid, eventually infecting the eye leading to blurred vision and a decrease in the field of vision (26). Conjunctivitis, more commonly known as "pink eye", results from inflammation of the conjunctiva that can be caused by bacteria, viruses, fungi, or parasites (79). With conjunctivitis, the entire conjunctiva is involved and there is often discharge (27), which leads to vision loss, moderate to severe pain, hypopyon, hyphema, pupil asymmetry, decreased pupil response, and trouble opening the eye or keeping the eye open (28). Infections, bacteria, and viruses, too can influence visual performance by altering color vision, causing a decrease in one's visual field, and reducing contrast sensitivity (24). Infections can thus significantly impact an individual's vision and need to be taken into consideration when testing athletes.

Retinal detachment (RD) can result from aging or from trauma, as commonly experienced during sports (31). De- 
tachment of the retina is serious, and can cause complete blindness. This is so since if the retina is detached from the choroid, the photoreceptors will fail (31). While retinal detachment causes sudden and painless loss of vision, in cases where there is not a full detachment, the athlete can experience blurred vision (31). With gradual $\mathrm{RD}$, floaters and flashes may occur in the eye in the weeks leading up to the detachment (31). In addition, $\mathrm{RD}$ can be accompanied by mild discomfort and redness due to associated uveitis and hypotony (31). Thus, RD can have a significant impact on an athlete's vision, especially in contact sports where trauma-related RD, sudden or gradual, can most easily occur.

Normal aging in athletes can affect vision since aging causes all the muscles of the body to deteriorate over time, influencing both activities of daily living (ADLs) and athletic performance (32). The same is true in relation to the eye muscles and their function. Other changes associated with aging include changes in the shape and tone of the ciliary bodies, as well as reduced elasticity of the lens capsule and compactness of the lens fibers. This leads to a decrease in the amplitude of accommodation resulting in presbyopia, hardening (nuclear sclerosis) of the lens, resulting in blurred vision (33). Aging also affects an athlete's vision through "wear and tear" and suggests that the body and its cells, including eye cells, are damaged by overuse and abuse, from such influences as, among others, ultraviolet (UV) rays from the sun, and excessive consumption of fat, sugar, caffeine, alcohol, and nicotine (33). This may be true of younger athletes who experience "accelerated aging", especially if they have been exposed to prolonged and extreme environmental conditions and diets throughout their careers (33).

A great problem for athletes is the finding that the act of engaging in exercise itself, either during training or competition, affects vision. Recent studies have demonstrated that prolonged exercise can cause brain-based fatigue in the corticospinal motor system, which impairs the oculomotor system. Specifically, three hours of strenuous cycling has been shown to reduce the velocity of rapid eye movements (moving your eye in a rapid manner from one object to another) independently of other visual processes (such as dorsal cortical processing stream function) (38). This may be a result of the neurotransmitter systems' experiencing significant perturbation during prolonged exercise (80). However, it is not known if enhanced physical conditioning may provide some fatigue-resistance to brain-based fatigue, and future studies could determine whether there is a relationship between physical conditioning and VSI in athletic populations.

For an athlete's visual system to perform optimally, the lighting of the area where testing, training or performance take place is crucial. Light-emitting diode (LED) bulbs seem to produce the same amount of light as incandescent bulbs, while saving power and being both energyand cost-efficient, but there is little consideration in the literature of their impact on visual comfort or ocular health (81). There is evidence that scotopic rich fluorescent source illumination (a type of LED lighting) improves visual acuity and decreases pupil size (46). The effect, however, is measurable only with low-contrast briefly-presented stimuli. Visual stimuli are influenced by the chromaticity of light (47) and Yamagishi et al. (48) found that visual performance, mood, and an individuals' perception of comfortable reading and visual task performance improved under artificial LED lighting. In a study performed by Mott et al. (49), it was found that, compared to natural lighting conditions, increasing the quality of artificial light positively affected the visual performance of participants. Since most visual testing studies have been conducted indoors, their findings could have been affected by the artificial lighting used and it is this comparative factor that may offer opportunities for future research.

\subsection{Limitations}

While an in-depth search was performed to find a large amount of previously known and unknown factors that could affect the vision of athletes, there is the possibility that there are other factors that could not be identified. This may be related to articles not being published in the English-language, the use of only published citations, and the use of the defined/selected databases due to time, budget, and resource constraints. In addition, the inclusion criteria may be considered either too narrow resulting in eligible evidence not being found or even too loosely defined increasing the possibility of poor reproducibility due to many subjective decisions regarding what to include.

\section{Conclusions}

Factor by factor, this review has highlighted areas for future research, pointing to opportunities to broaden the scope of the knowledge base. Fourteen factors affecting vision and VSI in athletes were identified, and this compilation provides a starting point for further factors to be added. This study reveals that many factors can affect vision and VSI and could add significantly to processes related to visual testing of athletes and assessments of their decision-making skills. This review further indicates that while current research still tends to focus on single factors affecting vision and VSI, a large number of such factors have been identified and empirically researched. This 
offers new opportunities for researchers to investigate the effects of a combination of factors, and for coaches to explore further possibilities for competitive advantage.

\section{Footnotes}

Authors' Contribution: Lourens Millard, Ina Shaw, and Brandon Stuwart Shaw made substantial contributions in the design of the study, acquisition, analysis, writing and critically reviewing of the article and its intellectual content, final approval of the manuscript, and agreeing to take responsibility for all aspects of the study. Gerrit Jan Breukelman made substantial contributions in writing and critically reviewing the article and its intellectual content, final approval of the manuscript, and agreeing to take responsibility for all aspects of the study.

Conflict of Interests: None declared by authors.

Ethical Approval: The study was approved by the Institutional Review Boards (no.: UZREC 171110-030 PGD 2019/24).

Funding/Support: None declared by authors.

\section{References}

1. Davids K. Visual perception and action in sport. London: Routledge; 1999.

2. Wimhurst Z. Visual skills of elite athletes. England: University of Surrey; 2012.

3. Schmidt RA, Lee TD. Motor control and learning: A behavioural emphasis. Champaign: Human Kinetics; 1999.

4. Baker J, Farrow D, Baker J, Farrow D. Routledge handbook of sport expertise. London: Routledge; 2015. doi: 10.4324/9781315776675.

5. Abernethy B. Enhancing sports performance through clinical and experimental optometry. Clin Exp Optom. 1986;69(5):189-96. doi: 10.1111/j.1444-0938.1986.tb04589.x.

6. Nieuwenhuys A, Pijpers JR, Oudejans RR, Bakker FC. The influence of anxiety on visual attention in climbing. J Sport Exerc Psychol. 2008;30(2):171-85. doi:10.1123/jsep.30.2.171. [PubMed: 18490789].

7. Moher D, Shamseer L, Clarke M, Ghersi D, Liberati A, Petticrew M, et al. Preferred reporting items for systematic review and metaanalysis protocols (PRISMA-P) 2015 statement. Syst Rev. 2015;4:1 doi: 10.1186/2046-4053-4-1. [PubMed: 25554246]. [PubMed Central: PMC4320440].

8. Aaen-Stockdale C, Hess RF. The amblyopic deficit for global motion is spatial scale invariant. Vision Res. 2008;48(19):1965-71. doi: 10.1016/j.visres.2008.06.012. [PubMed: 18625265].

9. Levi DM, Yu C, Kuai SG, Rislove E. Global contour processing in amblyopia.Vision Res. 2007;47(4):512-24. doi:10.1016/j.visres.2006.10.014 [PubMed: 17223155]. [PubMed Central: PMC1851910].

10. Hess RF, Wang YZ, Demanins R, Wilkinson F, Wilson HR. A deficit in strabismic amblyopia for global shape detection. Vision Res. 1999;39(5):901-14. doi: 10.1016/s0042-6989(98)00157-6. [PubMed: 10341944].

11. Quigley HA, Broman AT. The number of people with glaucoma worldwide in 2010 and 2020. Br J Ophthalmol. 2006;90(3):262-7. doi: 10.1136/bjo.2005.081224. [PubMed: 16488940]. [PubMed Central: PMC1856963].
12. Knudson D, Kluka DA. The impact of vision and vision training on sport performance. J Physic Educ Recreation Dance. 1997;68(4):17-24. doi: 10.1080/07303084.1997.10604922.

13. Sperduto RD, Seigel D, Roberts J, Rowland M. Prevalence of myopia in the United States. Arch Ophthalmol. 1983;101(3):405-7. doi: 10.1001/archopht.1983.01040010405011. [PubMed: 6830491].

14. Walsh NP, Fortes MB, Esmaeelpour M. Influence of modest changes in whole-body hydration on tear fluid osmolarity: important considerations for dry eye disease detection. Cornea. 2011;30(12):1517. author reply 1517-8. doi: 10.1097/ICO.0b013e31821ddd3a. [PubMed: 21849890].

15. Kostyuk O, Nalovina O, Mubard TM, Regini JW, Meek KM, Quantock AJ, et al. Transparency of the bovine corneal stroma at physiological hydration and its dependence on concentration of the ambient anion. J Physiol. 2002;543(Pt 2):633-42. doi: 10.1113/jphysiol.2002.021527. [PubMed: 12205195]. [PubMed Central: PMC2290503].

16. Digre KB. More than meets the eye: The eye and migraine-what you need to know. J Neuroophthalmol. 2018;38(2):237-43. doi: 10.1097/WNO.0000000000000660. [PubMed: 29738351].

17. Queiroz LP, Friedman DI, Rapoport AM, Purdy RA. Characteristics of migraine visual aura in Southern Brazil and Northern USA. Cephalalgia. 2011;31(16):1652-8. doi: 10.1177/0333102411430263. [PubMed: 22116942].

18. Friedman DI, Evans RW. Are blurred vision and short-duration visual phenomena migraine aura symptoms? Headache. 2017;57(4):643-7. doi: 10.1111/head.13042. [PubMed: 28181231].

19. Jacobson DM. Benign episodic unilateral mydriasis. Clinical characteristics. Ophthalmology. 1995;102(11):1623-7. doi: 10.1016/s01616420(95)30818-4. [PubMed: 9098253].

20. Drummond SP, Brown GG. The effects of total sleep deprivation on cerebral responses to cognitive performance. Neuropsychopharmacology. 2001;25(5 Suppl):S68-73. doi: 10.1016/S0893-133X(01)00325-6. [PubMed: 11682277].

21. Thomas M, Sing H, Belenky G, Holcomb H, Mayberg H, Dannals R, et al. Neural basis of alertness and cognitive performance impairments during sleepiness. I. Effects of $24 \mathrm{~h}$ of sleep deprivation on waking human regional brain activity. J Sleep Res. 2000;9(4):335-52. doi: 10.1046/j.1365-2869.2000.00225.x. [PubMed: 11123521].

22. Posner MI, Walker JA, Friedrich FJ, Rafal RD. Effects of parietal injury on covert orienting of attention. J Neurosci. 1984;4(7):1863-74. [PubMed: 6737043]. [PubMed Central: PMC6564871].

23. Bocca ML, Denise P. Total sleep deprivation effect on disengagement of spatial attention as assessed by saccadic eye movements. Clin Neurophysiol. 2006;117(4):894-9. doi: 10.1016/j.clinph.2006.01.003. [PubMed: 16497551].

24. Shah KH, Holland GN, Yu F, Van Natta M, Nusinowitz S; Studies of Ocular Complications of Aids Research Group. Contrast sensitivity and color vision in HIV-infected individuals without infectious retinopathy. Am J Ophthalmol. 2006;142(2):284-92. doi: 10.1016/j.ajo.2006.03.046. [PubMed: 16876510].

25. Kozak I, Bartsch DU, Cheng L, Kosobucki BR, Freeman WR. Objective analysis of retinal damage in HIV-positive patients in the HAART era using OCT. Am J Ophthalmol. 2005;139(2):295-301. doi: 10.1016/j.ajo.2004.09.039. [PubMed: 15733991]. [PubMed Central: PMC3757251].

26. Agarwal M, Gupta C, Gujral GS, Mittal M. Tinea corporis infection manifestating as retinochoroiditis-an unusual presentation.J Ophthalmic Inflamm Infect. 2019;9(1):8. doi: 10.1186/s12348-019-0173-z. [PubMed: 31131426]. [PubMed Central: PMC6535422]

27. Ramirez DA, Porco TC, Lietman TM, Keenan JD. Epidemiology of conjunctivitis in US emergency departments. JAMA Ophthalmol. 2017;135(10):1119-21. doi: 10.1001/jamaophthalmol.2017.3319. [PubMed: 28910427]. [PubMed Central: PMC5773254].

28. Ryder EC, Benson S. Conjunctivitis. USA: StatPearls Publishing LLC; 2019. 
29. Burch HB, Cooper DS. Management of graves disease: A review. JAMA. 2015;314(23):2544-54. doi: 10.1001/jama.2015.16535. [PubMed: 26670972].

30. Riguetto CM, Neto AM, Tambascia MA, Zantut-Wittmann DE. The relationship between quality of life, cognition, and thyroid status in Graves' disease. Endocrine. 2019;63(1):87-93. doi: 10.1007/s12020-0181733-y. [PubMed: 30173328].

31. Jalali S. Retinal detachment. Community Eye Health. 2003;16(46):25-6. [PubMed: 17491854]. [PubMed Central: PMC1705859].

32. Loewenfeld IE. Pupillary changes related to age, topics is neuro-'ophthalmology'. Baltimore: Williams \& Wilkins; 1979.

33. Salvi SM, Akhtar S, Currie Z. Ageing changes in the eye. Postgrad Med J. 2006;82(971):581-7. doi: 10.1136/pgmj.2005.040857. [PubMed: 16954455]. [PubMed Central: PMC2585730].

34. Fillion M, Lemire M, Philibert A, Frenette B, Weiler HA, Deguire JR, et al. Toxic risks and nutritional benefits of traditional diet on near visual contrast sensitivity and color vision in the Brazilian Amazon. Neurotoxicology. 2013;37:173-81. doi: 10.1016/j.neuro.2013.04.010. [PubMed: 23680050].

35. Lauritzen L, Hansen HS, Jorgensen MH, Michaelsen KF. The essentiality of long chain n-3 fatty acids in relation to development and function of the brain and retina. Prog Lipid Res. 2001;40(1-2):1-94. doi: 10.1016/s0163-7827(00)00017-5. [PubMed: 11137568].

36. SanGiovanni JP, Chew EY. The role of omega-3 long-chain polyunsaturated fatty acids in health and disease of the retina. Prog Retin Eye Res. 2005;24(1):87-138. doi: 10.1016/j.preteyeres.2004.06.002. [PubMed: 15555528].

37. Benolken RM, Anderson RE, Wheeler TG. Membrane fatty acids associated with the electrical response in visual excitation. Science.1973;182(4118):1253-4. doi: 10.1126/science.182.4118.1253. [PubMed: 4752217].

38. Connell CJ, Thompson B, Turuwhenua J, Srzich A, Gant N. Fatiguerelated impairments in oculomotor control are prevented by norepinephrine-dopamine reuptake inhibition. Sci Rep. 2017;7:42726. doi: 10.1038/srep42726. [PubMed: 28198465]. [PubMed Central: PMC5309883].

39. Taylor F. Drugs affecting the eye. Aust Fam Physician. 1985;14(8):744-5. [PubMed: 2864912].

40. Stewart SA. The effects of benzodiazepines on cognition. J Clin Psychiatry. 2005;66 Suppl 2:9-13. [PubMed: 15762814].

41. Lieberman J3. Managing anticholinergic side effects. Prim Care Companion J Clin Psychiatry. 2004;6(Suppl 2):20-3. [PubMed: 16001097]. [PubMed Central: PMC487008].

42. Correll CU, Detraux J, De Lepeleire J, De Hert M. Effects of antipsychotics, antidepressants and mood stabilizers on risk for physical diseases in people with schizophrenia, depression and bipolar disorder. World Psychiatry. 2015;14(2):119-36. doi: 10.1002/wps.20204. [PubMed: 26043321]. [PubMed Central: PMC4471960].

43. Younger JW, Chu LF, D’Arcy NT, Trott KE, Jastrzab LE, Mackey SC. Prescription opioid analgesics rapidly change the human brain. Pain. 2011;152(8):1803-10. doi: 10.1016/j.pain.2011.03.028. [PubMed: 21531077]. [PubMed Central: PMC3138838].

44. Kiss AJ, Mirarefi AY, Ramakrishnan S, Zukoski CF, Devries AL, Cheng $\mathrm{CH}$. Cold-stable eye lens crystallins of the Antarctic nototheniid toothfish Dissostichus mawsoni Norman. J Exp Biol. 2004;207(Pt 26):463349. doi: 10.1242/jeb.01312. [PubMed:15579559].

45. Regini JW, Grossmann JG, Timmins P, Harding JJ, Quantock AJ, Hodson SA, et al. X-ray- and neutron-scattering studies of alpha-crystallin and evidence that the target protein sits in the fenestrations of the alpha-crystallin shell. Invest Ophthalmol Vis Sci. 2007;48(6):2695-700. doi:10.1167/iovs.06-0559. [PubMed: 17525201].

46. McColl SL, Veitch JA. Full-spectrum fluorescent lighting: A review of its effects on physiology and health. Psychol Med. 2001;31(6):949-64. doi:10.1017/s0033291701004251. [PubMed: 11513381].
47. Wurtz RH, McAlonan K, Cavanaugh J, Berman RA. Thalamic pathways for active vision. Trends Cogn Sci. 2011;15(4):177-84. doi 10.1016/j.tics.2011.02.004. [PubMed: 21414835]. [PubMed Central PMC3070860].

48. Yamagishi M, Yamaba K, Kubo C, Nokura K, Nagata M. Effects of LED lighting characteristics on visual performance of elderly people. Gerontechnology. 2008;7(2). doi:10.4017/gt.2008.07.02.180.00.

49. Mott MS, Robinson DH, Walden A, Burnette J, Rutherford AS. Illuminating the effects of dynamic lighting on student learning. SAGE Open. 2012;2(2). doi: 10.1177/2158244012445585.

50. Eysenck MW, Calvo MG. Anxiety and performance: The processing efficiency theory. Cognit Emotion. 1992;6(6):409-34. doi: $10.1080 / 02699939208409696$.

51. Bittner AK, Edwards L, George M. Coping strategies to manage stress related to vision loss and fluctuations in retinitis pigmentosa. $O p$ tometry. 2010;81(9):461-8. doi: 10.1016/j.optm.2010.03.006. [PubMed: 20591747]. [PubMed Central: PMC2926200].

52. Moschos MM. Physiology and psychology of vision and its disorders: A review. Med Hypothesis Discov Innov Ophthalmol. 2014;3(3):8390. [PubMed: 25741524]. [PubMed Central: PMC4348490].

53. Meir R. Conditioning the visual system. Strength Cond J.2005;27(4):8692. doi: 10.1519/00126548-200508000-00015.

54. Williams AM, Davids K, Williams JG. Visual perception and action in sport.1st ed. New York: Routledge; 1999.

55. Moodley A. Understanding vision and the brain. Community Eye Health. 2016;29(96):61-3. [PubMed: 28381903]. [PubMed Central: PMC5365039].

56. McKee SP, Levi DM, Movshon JA. The pattern of visual deficits in amblyopia.JVis. 2003;3(5):380-405. doi:10.1167/3.5.5. [PubMed:12875634]

57. Curcio CA, Sloan KR, Kalina RE, Hendrickson AE. Human photoreceptor topography. J Comp Neurol. 1990;292(4):497-523. doi 10.1002/cne.902920402. [PubMed: 2324310].

58. Thein LA. Environmental conditions affecting the athlete. $J$ Or thop Sports Phys Ther. 1995;21(3):158-71. doi: 10.2519/jospt.1995.21.3.158. [PubMed: 7742842].

59. Walsh NP, Fortes MB, Raymond-Barker P, Bishop C, Owen J, Tye E, et al. Is whole-body hydration an important consideration in dry eye? Invest Ophthalmol Vis Sci. 2012;53(10):6622-7. doi: 10.1167/iovs.12-10175. [PubMed: 22952120].

60. Sabetti L, Renzetti A, D’Alessandri L, Balestrazzi E. Eventual error caused by dehydration with pachometry. Ophthalmologica. 2001;215(2):97-101. doi: 10.1159/000050837. [PubMed: 11244338].

61. Matsuura T, Ikeda H, Idota N, Motokawa R, Hara Y, Annaka M Anisotropic swelling behavior of the cornea. J Phys Chem B 2009;113(51):16314-22. doi:10.1021/jp907232h. [PubMed: 19954152].

62. Scott JA. A finite element model of heat transport in the human eye. Phys Med Biol. 1988;33(2):227-41. doi: 10.1088/0031-9155/33/2/003. [PubMed: 3362966].

63. Ocon AJ. Caught in the thickness of brain fog: exploring the cognitive symptoms of chronic fatigue syndrome. Front Physiol. 2013;4:63. doi: 10.3389/fphys.2013.00063. [PubMed: 23576989]. [PubMed Central: PMC3617392].

64. Woodman T, Hardy L. Stress and anxiety, handbook of sport psychology New York: John Wiley \& Sons; 2001.

65. Filaire E, Sagnol M, Ferrand C, Maso F, Lac G. Psychophysiological stress in judo athletes during competitions.J Sports Med Phys Fitness. 2001;41(2):263-8. [PubMed: 11447372]

66. Dinges DF, Kribbs NBP. erforming while sleepy: Effects of experimentally induced sleepiness. Chichester: Wiley; 1991.

67. Smith TJ,Hegedus L. Graves' disease. NEngl JMed.2016;375(16):1552-65. doi: 10.1056/NEJMra1510030. [PubMed: 27797318].

68. Nienhueser J, Brown GA, Shaw BS, Shaw I. Effects of energy drinks on resting and submaximal metabolism in college age males. Int J Exerc Sci. 2009;4(1):65-76. 
69. Soppi ET. Iron deficiency without anemia - a clinical challenge. Clin Case Rep. 2018;6(6):1082-6. doi: 10.1002/ccr3.1529. [PubMed: 29881569]. [PubMed Central: PMC5986027].

70. Stoykovich S, Gibas K. APOE epsilon4, the door to insulin-resistant dyslipidemia and brain fog? A case study. Alzheimers Dement (Amst). 2019;11:264-9. doi: 10.1016/j.dadm.2019.01.009. [PubMed: 30923733]. [PubMed Central: PMC6423699].

71. Lynall M. Neuropsychiatric symptoms in lupus. Lupus. 2018;27(1_suppl):18-20. doi: 10.1177/0961203318801672. [PubMed 30452327].

72. Kalb RC. Multiple sclerosis: The questions you have, the answers you need. USA. Demos Medical Publishing; 2000.

73. Shin SY, Katz P, Wallhagen M, Julian L. Cognitive impairment in persons with rheumatoid arthritis. Arthritis Care Res (Hoboken). 2012;64(8):1144-50. doi: 10.1002/acr.21683. [PubMed: 22505279]. [PubMed Central: PMC3744877].

74. Theoharides TC, Stewart JM, Hatziagelaki E, Kolaitis G. Brain "fog," inflammation and obesity: key aspects of neuropsychiatric disorders improved by luteolin. Front Neurosci. 2015;9:225. doi 10.3389/fnins.2015.00225. [PubMed: 26190965]. [PubMed Central: PMC4490655].

75. Samuels MH. Psychiatric and cognitive manifestations of hypothyroidism. Curr Opin Endocrinol Diabetes Obes. 2014;21(5):377-83. doi:
10.1097/MED.0000000000000089. [PubMed: 25122491]. [PubMed Central: PMC4264616].

76. Farooqi AM, Padilla JM, Monteith TS. Acute confusional migraine: Distinct clinical entity or spectrum of migraine biology? Brain Sci. 2018;8(2). doi: 10.3390/brainsci8020029. [PubMed: 29414874]. [PubMed Central: PMC5836048].

77. Huber JD. Diabetes, cognitive function, and the bloodbrain barrier. Curr Pharm Des. 2008;14(16):1594-600. doi: 10.2174/138161208784705441. [PubMed: 18673200].

78. Clem KL, Borchers JR. HIV and the athlete. Clin Sports Med. 2007;26(3):413-24. doi:10.1016/j.csm.2007.04.012. [PubMed: 17826192].

79. Alfonso SA, Fawley JD, Alexa Lu X. Conjunctivitis. Prim Care. 2015;42(3):325-45. doi:10.1016/j.pop.2015.05.001. [PubMed: 26319341].

80. Hasegawa H, Piacentini MF, Sarre S, Michotte Y, Ishiwata T, Meeusen $\mathrm{R}$. Influence of brain catecholamines on the development of fatigue in exercising rats in the heat. J Physiol. 2008;586(1):141-9. doi: 10.1113/jphysiol.2007.142190. [PubMed: 17947314]. [PubMed Central: PMC2375558].

81. Ram MS, Bhardwaj R. Effect of different illumination sources on reading and visual performance. J Ophthalmic Vis Res. 2018;13(1):44-9. doi: 10.4103/jovr.jovr_50_17. [PubMed: 29403589]. [PubMed Central: PMC5782456]. 